\title{
Fluxo do esgotamento: interrogando o processo de produção do tempo/ cansaço no internato médico
}

\author{
Exhaustion flow: investigating the process of producing time/tiredness in medical internship \\ Suellen Magalhães Dias Oliveira' (D) $\mid$ sue_magalhaes@yahoo.com.br \\ Mariana Hasse ${ }^{1}$ (1) mhasse@ufu.br \\ Flávia do Bonsucesso Teixeira' (1) flavia.teixeira@ufu.br
}

\section{RESUMO}

Introdução: A síndrome de burnout causa repercussão com impactos individuais, sociais e econômicos. A tríade que representa a síndrome acomete milhões de trabalhadores pelo mundo, incluindo os trabalhadores da área da saúde e, entre eles, os médicos. Pesquisas apontam um incremento das taxas de burnout entre médicos e residentes, mas pouco se fala sobre a síndrome em estudantes de Medicina.

Objetivo: Ao observarmos o adoecimento constante de estudantes, identificamos a necessidade de compreender mecanismos que possam ser considerados disparadores. Assim, investigamos a percepção dos estudantes de Medicina que cursam o estágio supervisionado sobre a síndrome de burnout e a autoidentificação dos sintomas.

Método: Realizamos pesquisa qualitativa do tipo estudo de caso utilizando grupo focal como ferramenta metodológica. Participaram desta pesquisa 22 internos divididos em três grupos focais. As falas foram analisadas segundo a análise de conteúdo.

Resultados: Dessas análises e de suas inferências, delinearam-se quatro categorias: "(Con)fusão de papéis: o processo de deixar de ser estudante"; "Uma síndrome (in)visível: a banalização do sofrimento"; "Tornar-se médico: forjado no sofrimento"; "(Des)identificação: efeitos de um processo nada fácil".

Conclusão: Os estudantes desconheciam a síndrome e não foram capazes de reconhecer os sintomas dela durante a formação. $\mathrm{O}$ achado significativo apontou para a sobrecarga relacionada à falta de tempo e como esta gera um processo de sofrimento nos estudantes. Acredita-se, portanto, que o processo de ensino precisa ser repensado para que os estudantes possam, de fato, aprender e apreender todos os significados que a universidade tem potencialmente a lhes oferecer.

Palavras-chave: Educação Médica; Esgotamento Psicológico; Estudantes; Saúde Mental.

\section{ABSTRACT}

Introduction: Burnout syndrome has individual, social and economic impacts. The triad that represents the syndrome affects millions of workers around the world, including healthcare workers and, among them, doctors. Research points to an increase in burnout rates among doctors and residents, but little is said about the syndrome in medical students.

Objective: By observing students constantly falling ill, we identified the need to understand mechanisms that can be considered triggers. Thus, we investigated how medical interns viewed Burnout Syndrome and the self-identification of symptoms.

Method: We carried out qualitative case study research using a focus group as a methodological tool. Twenty-two medical students participated in this study, divided into 3 focus groups. The statements were submitted to Content Analysis.

Results: From these analyses and their inferences, four categories were outlined: '(Con)fusion of roles: the process of ceasing to be a student'; 'A (in)visible syndrome: the trivialization of suffering'; 'Becoming a doctor: forged in suffering'; '(Mis)identification: effects of a far from easy process'.

Conclusion: Students were unaware of the syndrome and were unable to recognize its symptoms during training. The significant finding pointed to the burden related to lack of time and how it generates a process of suffering in students. Thus, it is believed that the teaching process needs to be rethought so that students can, in fact, learn and grasp all the meanings that the University potentially has to offer.

Keywords: Medical Education; Psychological Burnout; Students; Mental Health.

1 Universidade Federal de Uberlândia, Uberlândia, Minas Gerais, Brasil.

Editora-chefe: Daniela Chiesa

Editor associado: Izabel Cristina Meister Martins Coelho

Recebido em 09/07/20; Aceito em 02/11/20.

Avaliado pelo processo de double blind review. 


\section{INTRODUÇÃO}

Durante o curso de Mestrado Profissional em Saúde da Família (ProfSaúde), o objeto de estudo sobre o qual a pesquisadora principal se debruçaria foi angustiadamente perseguido. Como preceptora do estágio em saúde coletiva, acompanhava relatos dos estudantes que frequentemente reportavam cansaço extremo, prejuízo da vida social, sentimento de tristeza e ansiedade, medo do futuro e insegurança no presente. A pesquisadora passou a desconfiar que o esgotamento profissional estaria inserido no universo acadêmico.

Os estudantes de Medicina podem ter sua qualidade de vida deteriorada por sintomas mentais provenientes, entre outros aspectos, da realidade multifacetada - e talvez paradoxal - que promete status, glória e poder e entrega dor, morte e falibilidade. Esses estressores psicossociais, presentes constantemente durante o curso de Medicina, podem levar os estudantes a manifestar a síndrome de burnout, evidenciada por exaustão emocional, cinismo e baixa realização profissional'

A síndrome de burnout apresenta sintomas como irritabilidade, ansiedade, manifestações físicas, como mialgia e cefaleia, e ainda comprometimento das relações interpessoais e sociais. Desde a sua definição, feita por Freudenberger em 1974, o esgotamento dos recursos físicos e mentais é observado e, muitas vezes, relacionado ao objetivo de atingir uma meta inalcançável².

Foram identificados três aspectos principais para definir a síndrome: exaustão emocional, despersonalização e baixa realização pessoal. $\mathrm{O}$ aspecto da exaustão emocional se refere à perda de recursos emocionais, com o sentimento de que não se é mais capaz de avançar. A dimensão da despersonalização é referida como uma insensibilidade em relação ao outro que acarreta a percepção do indivíduo de que ele é, de certa forma, merecedor de seus problemas. E, por último, a baixa realização pessoal que faz alusão à tendência de o indivíduo se autoavaliar negativamente, principalmente no trato direto com as pessoas, estando presentes tristeza e insatisfação com o trabalho ${ }^{3}$.

Essa interpretação para o conceito de burnout foi tão relevante que, apesar de ter sofrido modificações principalmente para ampliar o enquadramento do significado em outras profissões -, ainda mantém a tríade conceitual de origem e é o termo mais utilizado na literatura da área ${ }^{4}$.

O problema pode estar presente em diversas profissões, mas aquelas que exigem relações pessoais diretas são mais acometidas $^{5}$. Os médicos representam a classe trabalhadora com maior nível de estresse ${ }^{6}$.

Apesar de estar atrelado às relações de trabalho, o termo burnout é descrito para diagnosticar também estudantes, que cada vez mais têm sofrido com a síndrome ${ }^{7}$. Embora não estejam inseridos formalmente no mercado de trabalho, os estudantes de Medicina passam a maior parte de sua formação em serviço e, nesse cenário de prática, vivenciam experiências que podem ser fatores estressores para seu desenvolvimento profissional ${ }^{8}$.

A segunda causa mais prevalente de morte entre estudantes de Medicina é o suicídio. Considerando a população em geral, o fenômeno sobressai, e as causas identificadas têm sido separação da família e dos amigos, transtornos psiquiátricos - como depressão e abuso de substâncias -, privação de sono, estresse, medo de errar e sobrecarga de atividades ${ }^{9}$.

O processo de educação médica pode influenciar na saúde mental e na qualidade de vida dos acadêmicos. Os estudantes sofrem com maior nível de angústia se comparados a outros estudantes da mesma idade. Para alguns autores, as experiências desses estudantes variam ao longo da formação, e, a cada ano, gradualmente, os níveis de ansiedade, estresse e burnout aumentam ${ }^{8,10-12}$.

Diferentemente, Mota et al. ${ }^{13}$ acreditam que a prevalência de ansiedade e depressão não é diretamente proporcional à progressão na formação acadêmica. Os autores afirmam que, nos dois últimos anos da graduação, a possibilidade de sofrimento se intensifica, pois o curso de Medicina proporciona aos estudantes o seu nível de maior intimidade com serviços - e, consequentemente, com pacientes -, experiência mais próxima do universo dos trabalhadores de saúde.

Nessa perspectiva, este trabalho buscou percepções de estudantes de Medicina que cursam o internato sobre o burnout em sua própria realidade. Tal intento se faz relevante diante do cenário atual de adoecimento psíquico da população em geral, mas especialmente de médicos, que tem se deparado com mudanças e perdas de direitos na realidade do trabalho em saúde ${ }^{14}$.

\section{METODOLOGIA}

Realizamos uma pesquisa qualitativa do tipo estudo de caso, que consiste na articulação de fatores para compreender um contexto particular ${ }^{15}$. A escolha se ancorou na definição do problema de pesquisa que se delineou a partir da seguinte questão:

- Como os estudantes do internato percebem os sintomas da síndrome de burnout nos pacientes de que cuidam, nos seus pares e em si próprios?

Esta pesquisa foi aprovada pelo Comitê de Ética em Pesquisa com Seres Humanos da universidade em que foi realizado o estudo, sob parecer $n^{\circ}$ 3.039.525.

\section{Participantes da pesquisa}

Um novo currículo do curso de Medicina foi adotado na universidade federal local do estudo em 2013, orientado para 
um modelo de ensino com educação centrada no estudante e atenta à saúde mental dele ${ }^{16}$. É sobre estudantes que ingressaram nas primeiras turmas nesse novo currículo que se fala neste trabalho.

A primeira turma a integralizar o curso de Medicina com o novo currículo estava no último semestre por ocasião da pesquisa, e os demais estavam matriculados no nono, décimo e $11^{\circ}$ períodos, respectivamente. Todos foram convidados. Por fim, participaram da pesquisa 22 estudantes de Medicina: sete do nono período, dez do $11^{\circ}$ e cinco do $12^{\circ}$.

\section{Produç̧ão de dados}

Os dados foram produzidos a partir de grupos focais. A opção por esse instrumento mostrou-se adequada, pois o objetivo era, a partir de questões, obter respostas de um todo, identificando o conteúdo do discurso produzido na interação entre os diferentes participantes ${ }^{17}$.

Em razão de sua atuação como preceptora do internato, a pesquisadora principal deste estudo atuou como observadora nos grupos, que foram todos conduzidos por uma pesquisadora com experiência e que não tinha contato prévio com os estudantes.

O roteiro para os grupos focais foi construído e organizado em três eixos:

- Eixo 1: Reconhecendo o que é burnout (nos usuários, nos pares e em si mesmos).

- Eixo 2: Como os participantes se posicionam em relação aos sintomas de burnout (dos outros e de si mesmos).

- Eixo 3: Causas, consequências da síndrome e observações.

Em sala de aula, entregou-se um convite impresso aos estudantes do internato (matriculados do nono ao $12^{\circ}$ período). Por meio de um aplicativo, um convite digital foi enviado pelos representantes de turma. Os grupos foram divididos conforme o período em curso e nomeados por algarismos cardinais na ordem em que ocorreram, denominando-se assim: grupo 1 ( $11^{\circ}$ período), grupo $2\left(12^{\circ}\right.$ período) e grupo 3 (nono período). Todas as atividades da pesquisa foram realizadas nas dependências da universidade, em horário previamente pactuado com os estudantes.

O tempo médio de duração de cada grupo foi de 90 minutos. Em áudio e vídeo, gravou-se a participação dos grupos, e as falas foram posteriormente transcritas na íntegra de forma não identificada para garantia do sigilo. O material da gravação foi apagado.

\section{Análise dos dados}

Os dados obtidos foram analisados segundo as etapas descritas para a análise de conteúdo temático ${ }^{18}$. Esse recurso metodológico proporciona, por meio da inferência, a possibilidade de interpretação do que foi dito em palavras e do não dito. Dessas análises e consecutivas inferências, delinearam-se quatro categorias: "(Con)fusão de papéis: o processo de deixar de ser estudante"; "Uma síndrome (in)visível: a banalização do sofrimento”; "Tornar-se médico: forjado no sofrimento"; e "(Des)identificação: efeitos de um processo nada fácil". Iniciamos a apresentação dos resultados e a discussão com uma pequena categoria, emergente, inusitadamente, pela ausência de participação.

\section{RESULTADOS E DISCUSSÃO}

\section{Sobre (não) ter tempo...}

Os estudantes matriculados no décimo período do curso não aceitaram o convite para participar da pesquisa. A justificativa era de que não seria possível compatibilizar a carga horária das atividades previstas para o estágio supervisionado com o tempo para participação no grupo focal. O convite foi realizado três vezes, em momentos diferentes. A resposta do conjunto dos estudantes era que seria indispensável a liberação de carga horária referente ao estágio para participação no estudo.

Não buscamos apoio formal na coordenação do curso de Medicina para isso, por entendermos que tal solicitação - e potencial autorização - poderia repercutir, uma vez que diversas pesquisas ocorrem nos espaços da universidade. Na busca por essa liberação, tentamos estratégias negociadas diretamente com os coordenadores/preceptores, mas também não obtivemos êxito.

A ausência desses estudantes a partir da justificativa apresentada se entrelaça com os achados nos grupos realizados com os outros períodos. A difícil tarefa de administrar o tempo parece ser um elemento que envolve o cotidiano desses estudantes de forma significativa. Segundo Gonçalves ${ }^{19}$, uma das principais queixas dos internos de Medicina é a escassez do tempo, que se reflete muito nas questões sociais, como a falta de lazer. Somado a isso, a realização de escalas mal organizadas leva os estudantes a uma sensação de falta de controle sobre a própria agenda.

\section{(Con)fusão de papéis: o processo de deixar de ser estudante}

A primeira categoria de nosso trabalho resulta das percepções dos estudantes sobre como suas atribuições durante o ciclo profissionalizante produzem um sujeito híbrido, ora médico, ora estudante, o que redunda em incertezas, inseguranças e sentimentos de exploração.

$O$ ingresso no ciclo profissionalizante promove um deslocamento no qual estudantes de graduação em Medicina 
passam a ser nomeados como "internos". Esse processo parece funcionar como um ritual no qual deixam de ser considerados ainda que de forma equivocada - estudantes sem que tenham adquirido o status de profissionais: "Na apresentação de como seria o internato, teve uma pressão assim: 'Agora vocês não são mais alunos, não são nem alunos e nem médicos, estão no meio-termo, e a equipe conta com vocês" (Grupo 3).

Esse sentimento confuso sobre que papel exercem e em que lugar estão é gerado e fomentado por usuários do serviço, docentes, preceptores, residentes e outros estudantes do curso. Os internos falam sobre uma rotina de serviço centrada e dependente da presença deles, o que parece reafirmar que são trabalhadores da instituição.

Olha o tanto que está errado: nas escalas dos residentes, nas escalas dos chefes, é tudo programado pensando nos internos. Quando a gente tira férias, eles mudam as coisas para poder dar conta. Então eles fecham os ambulatórios, chamam os residentes para ir para os prontos-socorros, ou seja, sem a gente, não anda. Se hoje a gente para de greve, o hospital para. $O$ povo ia ficar louco atrás da gente (Grupo 2).

Vemos um hospital-escola que não se organiza em função do ensino, mas para o atendimento da demanda e, assim, produz situações que reafirmam aos estudantes essa percepção nebulosa sobre as funções deles. Tal percepção, de que o serviço é dependente da presença dos estudantes, gera uma sensação negativa de pertencimento ao quadro de funcionários do hospital.

Ainda que uma percepção dissonante tenha aparecido no grupo, sua interpretação aponta para o exercício de um papel que afasta ou oblitera o lugar de estudante: "Pra mim é maravilhoso! Eu venho aqui pra trabalhar, e é isso que eu quero: é trabalhar!" (Grupo 1).

Esse processo de entrada precoce no mercado de trabalho é compreendido como injusto, "porque a gente tem todas as obrigações e deveres de qualquer profissional que está trabalhando no hospital, exceto os direitos" (Grupo 1) fala seguida por risos do grupo todo. Esse fato é reafirmado pelas mudanças na relação da instituição com os estudantes. Isso ocorre porque a estrutura dos estágios produz um distanciamento com os demais estudantes da graduação:

A gente tem muito menos férias, a gente tem uma semana a cada três meses. Então, aquelas férias de fim de ano de dois meses pra gente dar uma renovada, não existe mais! Para sempre! Agora só aposentando, se aposentar algum dia (Grupo 3 - essa intervenção foi acompanhada por risos do grupo todo).

O período de férias demarca o intervalo entre os semestres letivos e aponta para um processo de progressão nos estudos que, no estágio supervisionado, passa a ser menor e dividido por áreas e escalas que não seguem o calendário do ano letivo, o que reafirma sua condição de excepcionalidade.

A Resolução do Conselho de Graduação ${ }^{20}$ assegura ao estagiário um período de 30 dias de recesso por ano de atividade desempenhada preferencialmente durante as férias escolares. No entanto, as Normas do Estágio Curricular Obrigatório ${ }^{21}$ da instituição preveem quatro semanas de férias anuais, e esse recesso é ofertado de forma a atender às necessidades dos serviços de saúde, e não às necessidades dos estudantes.

Assim, apesar de a legislação ${ }^{21}$ estabelecer a proteção do tempo do estudante para dedicar-se à preparação para as avaliações, isso não é identificado nos relatos dos participantes. Os estudantes possuem alguns momentos previstos em suas escalas como áreas pró-estudo ou pós-plantão que, na prática, não têm relação direta com avaliações marcadas ou com suporte para o discente, mas trata-se de soluções para tornar funcionais as escalas dos estágios e não extrapolar a carga horária prevista. Ou seja, tudo estabelecido a partir do interesse do serviço e não da necessidade de aprendizagem.

Assim, a ausência de espaço protegido para o estudo e as metodologias utilizadas no processo de ensino-aprendizagem reafirmam, equivocadamente, que o estágio supervisionado não seria mais um momento de aprender. Todo o conhecimento deveria ter sido adquirido anteriormente.

Você não sabe alguma coisa, você não sabe lidar com aquilo, mas você não pode não saber, você não pode errar um exame físico, você não pode errar uma anamnese, senão você é julgado, senão você vira piada. Se você fala algum termo errado, se na hora você confundiu... Ainda tem uma visão muito negativa do erro do estudante. [...] O erro não é visto como uma ferramenta pedagógica (Grupo 2).

A obrigatoriedade da presença em todas as atividades também é objeto de questionamento dos estudantes e aparece para estabelecer uma diferença com o período que eles nomeiam como "graduação". As Normas do Estágio Curricular Obrigatório ${ }^{21}$ preveem $100 \%$ de assiduidade nas atividades práticas, o que conflita com as normativas da própria instituição de ensino ${ }^{22}$.

Por consequência, há um processo ensino-aprendizagem desarticulado do currículo proposto e dos processos metodológicos preconizados pelo Projeto Político Pedagógico do curso ${ }^{22}$. A distância entre os ciclos que compõem a formação é aprofundada pelas relações entre docentes/preceptores e discentes no cotidiano do hospital. A relação que se estabelece distorce um padrão de organização de funções e estabelece entre chefes e subordinados uma relação de subordinação que inflige ao de menor poder sentimentos de humilhação e desprestígio.

A pressão por resultados também se modifica e não se 
resume mais somente a avaliações. A responsabilidade pelo usuário é interpretada como mais um desafio.

Não é um bom trabalho. Existe um trabalho que a pessoa vai trabalhar, volta pra casa, esquece o trabalho, descansa, tem o seu tempo com a família. A gente chega em casa, tem que estudar, tem que se comprometer com um paciente porque é um caso que chamou atenção, que você vai cuidar dele amanhã (Grupo 2).

Na lida com as pessoas sob seus cuidados, o estudante presencia o sofrimento humano, os dilemas éticos, as questões da vida e até da morte. Tal exposição é entendida pelo estudante como um grande fator estressor" ${ }^{23}$ : "eu tenho uma paciente. A paciente fala que tá entregando a vida dela pra mim, que a vida dela está nas minhas mãos. Olha o peso disso! Quem sou eu aqui?" (Grupo 1).

O preceptor, que teria uma função de destaque na formação do estudante no cenário de prática - inclusive para ampará-lo em suas angústias -, ainda não tem uma definição bem estabelecida sobre suas atribuições. Muitas vezes esse profissional está desarticulado da proposta do curso, dos docentes, dos coordenadores, enfim, do restante dos atores envolvidos no processo de formação do médico ${ }^{24}$. Assim, a confusão de papéis também atravessa a relação entre ensino e assistência no tocante à preceptoria e às funções dela - que não parecem evidentes aos que exercem essa atividade.

Eu acho que esse aqui [preceptor] é o pior, que ele não toca o serviço e fala: "Não gosto de alunos". [...] Ele deixa o serviço para a gente, mas ele não gosta da gente. Você teria que discutir com ele, só que ele não gosta de você. Ele não queria que você tivesse ali fazendo o serviço, mas ao mesmo tempo ele não quer ir lá fazer (Grupo 2).

Nesse cenário, também não se questiona a ausência do preceptor no local do ensino, e qualquer tentativa de mudança nessa situação é recebida como ameaça.

A gente sabe que a nossa estrutura hierárquica tem ameaça de retaliação de partes superiores... hierarquias... a gente já realmente, inclusive, escutou coisas assim... que a gente tem que tomar cuidado porque a corda sempre arrebenta para o lado mais fraco. Nós estávamos sendo ameaçados! (Grupo 1).

Segundo a Câmara Temática do Médico Jovem do Conselho Regional de Medicina do Estado de São Paulo ${ }^{25}$, em cartilha elaborada sobre assédio moral ao médico e ao estudante de Medicina, tal constrangimento pode se dar, entre outras formas, sob situações de humilhação e sobrecarga de tarefas, o que traz resultados muito negativos, como queixas relacionadas a saúde psicológica, estresse e baixa realização profissional, sintomas intrinsecamente relacionados à síndrome de burnout.
Quem exerce papel de educador precisa aprender a ensinar em meio a um ambiente em que o erro e o não saber devem ser parte do processo de aprendizagem, sem que coloque o cuidado do usuário em risco. A presença do preceptor e a garantia de que todo o processo será realizado sob a supervisão seriam a estratégia adequada para evitar o dano e assegurar a relação.

Sem direito ao descanso e ao lazer, o estudante também não pode errar. Esses fatores reafirmam um sofrimento que não existe como possibilidade para aqueles que deveriam diagnosticá-lo. Assim, seu reconhecimento como fator de adoecimento dos usuários também é negado"26: "Eu estou ali sozinha para cuidar dele [do paciente] porque eu tenho que ficar procurando residente no WhatsApp, eu não tenho chefe lá na enfermaria. Acontece essas coisas. É pesadíssimo!" (Grupo 3).

\section{Uma síndrome (in)visível: a banalização do sofrimento}

Não bastasse a falta de definições quanto às atribuições de cada cargo ou função, os estudantes trazem questões referentes à desvalorização do sofrimento. Trata-se de fenômeno notadamente percebido no cenário social que também repercute nas atitudes dos profissionais de saúde e contribui, implicitamente, para consolidar um imaginário de banalização de queixas ou sintomas que podem integrar o burnout.

Podemos afirmar que, em nenhum dos grupos, os estudantes demonstraram reconhecer a síndrome de burnout. Nem nos usuários que atenderam ao longo da formação e nem mesmo na própria experiência e/ou dos colegas: “Eu não me sinto preparada pra identificar alguém com burnout. A gente não é treinado para reconhecer esse padrão... acho que eu atendi muitos pacientes que tinham burnout e eu não... não parei para pensar nisso..." (Grupo 1).

A síndrome é marcada como uma (não) possibilidade, interditada como algo que não deve ser desvelado - inclusive para o estudante de Medicina. Consequentemente, esse suposto silenciamento se estende para a vida profissional do médico ${ }^{27}$.

Eu acho essa questão especificamente do burnout, eu não sei o que a gente poderia fazer de fato pela pessoa. Porque na depressão, você vai lá e trata, mas a gente não tem respaldo nenhum para saber o que fazer com essa pessoa. A maioria das empresas não vai aceitar um atestado disso. Aqui no curso de Medicina, que deveria cuidar disso, não aceita. [...] Eu falei assim: "Eu não dou conta mais, eu não dou conta!". E aí eu fui afastada, e, quando eu cheguei com atestado, eles falaram: "A gente não pode te afastar porque a atividade é prática, e não existe reposição". Mas eu não dou conta de vir é justamente por causa dessa atividade (Grupo 1).

O direito de cuidar da própria saúde, representado 
pelo atestado médico, pressupõe o reconhecimento de que existe um adoecimento que limita o exercício da função. Algo impossível para estudantes de Medicina no internato que parece funcionar como um lembrete de como a futura prática profissional deverá ser balizada.

Isso é uma questão cultural. Quando você fala que quer se formar e trabalhar 40 horas semanais, pronto, começam a dizer: "Ah, você quer ser médico e você quer trabalhar só 40 horas semanais? Impossível! Você tem que trabalhar mais do que isso, você vai trabalhar todos os dias, muitas horas por dia, ter três empregos..." (Grupo 3).

A dimensão ética do cuidado-e do ensino também-acaba desaparecendo nesse processo de banalização do sofrimento. Esse artifício, muitas vezes, funciona como uma defesa contra a consciência dolorosa da própria vulnerabilidade, representa sérios limites à produção do cuidado ${ }^{28,29}$ e pode ter sérias consequências na vida dos próprios profissionais e estudantes.

De acordo com Santa e Cantilino ${ }^{30}$, o suicídio entre médicos e estudantes de Medicina é maior do que na população geral de trabalhadores e de acadêmicos, e as motivações dessa tragédia referem-se à abnegação associada à profissão e às tentativas (inglórias, diga-se de passagem) de sustentar o estereótipo do médico super-herói.

\section{Tornar-se médico: forjado no sofrimento}

Nessa categoria, a discussão foca a formação acadêmica e sua ancoragem em dispositivos de sofrimento, materializados especialmente em uma rotina do não tempo. Nesse cenário, a responsabilidade pela administração do (im)possível é tarefa a ser aprendida muito antes de ingressar no ciclo profissionalizante - talvez, até na própria universidade.

Esse aprendizado baseado no sofrimento é causa e resultado da sua naturalização em um círculo vicioso alimentado pelas agruras sofridas e tomadas como necessárias ao ensino médico. Nessa engrenagem, que perpetua a naturalização do sofrimento, ocorre uma alternância de lugares que se caracteriza por passar a poder-fazer-sofrer: "A gente acaba vivendo, internalizando muito isso e, assim... a gente fala: "Eu não vou ser essa pessoa". E aí quando percebe, a gente está sendo" (Grupo 1).

Muitas vezes que rodei na clínica, eu peguei residentes R1 terminando o primeiro ano da residência falando: "Agora eu quero ver! Eu quero ver esse povo sofrer mesmo, igual eu sofri! Eles vão chegar aqui nesse PS e ficar a semana inteira". Às vezes a gente internaliza isso, inconscientemente a gente vai fazendo isso... $e$ piora cada vez mais (Grupo 1).

Muitas vezes o agente causador do constrangimento age da maneira como entende ser necessária, ou como pensa que se espera dele, em um processo de desqualificação que os estudantes não conseguem nomear como "assédio": "Tem professor, preceptor, residente que faz questão de fazer você se sentir medíocre, se sentir incompetente. Acham que aquilo te impulsionaria a estudar mais, a ser melhor no que você estava fazendo" (Grupo 3).

Em pesquisa ${ }^{31}$ realizada em um curso de graduação em Medicina, 75\% dos estudantes relatam já ter sofrido algum tipo de assédio (verbal/psicológico, físico e/ou sexual) no ambiente acadêmico. Os docentes e preceptores foram citados como os maiores assediadores nesse contexto, o que revela a grande prevalência de violência institucional no processo educacional.

Entretanto, esses conflitos não se restringem aos ambientes da formação e acompanham os estudantes também em suas interações sociais. A reprodução e perpetuação dos comportamentos assediadores fora do ambiente acadêmico endossam o entendimento de que o sofrimento psíquico é algo menor e reafirmam a percepção de que quem sofre é fraco e está errado.

Eu acho que aí que está o problema: é uma cobrança muito interna e alimentada pelo ambiente que você está convivendo. E você não consegue se livrar dela porque as pessoas do seu convívio estão reforçando ela o tempo todo ao invés de te amparar, de te acolher, de desconstruir (Grupo 3).

Nesse cenário, que consome todas as energias, a expectativa - pessoal e social - de sucesso no futuro parece sobrecarregar ainda mais quem não consegue planejar nem o dia seguinte:

Eu vou ser o primeiro médico da família toda, como muita gente aqui. Então dá uma pressão muito grande desse lado também. Então, as pessoas acham que você vai formar e vai virar milionário, que você vai ficar rico, que você vai ajudar todo mundo, você vai pagar silicone (Grupo 1).

O status social que a profissão médica carrega se estende ao estudante que, ao ocupar um lugar para poucos, busca um exercício de perfeição que impede, pelo menos de maneira alegórica, o sofrimento. Reforçando o pensamento do senso comum, a família de cada candidato a médico sobrecarrega-o com expectativas irreais e com a ideia de que, de fato, tal profissão é garantia de sucesso ${ }^{32}$.

Assim, muitas vezes, a morte deixa de ser uma figura de linguagem e se torna a única alternativa para desvelar a dor decorrente da impossibilidade de mudança ou desistência: "Já ouvi colega dizendo que, às vezes, a única alternativa pra conseguir abandonar um curso de Medicina, desistir da faculdade, é se matar. Tem muita pressão pra não largar, a família diz que não 
pode. Se morrer pelo menos acaba o curso" (Grupo 3).

\section{(Des)identificação: efeitos de um processo nada fácil}

Dando seguimento ao entendimento das consequências desse processo, na quarta e última categoria são trabalhadas as percepções sobre como esse contexto influencia o cotidiano dos estudantes e as estratégias para lidar com o sofrimento que, mesmo não dito, é vivido.

Mesmo não reconhecendo o burnout em si mesmos, os estudantes descrevem a vivência de diversos sintomas associados à síndrome, sem nomeá-los como tal: "Ah, eu acho que eu estava tão cansada que eu desisti de sofrer, daí eu continuei sofrendo, mas, assim, eu não queria pensar a respeito" (Grupo 3).

Eu tô ótima, de repente eu, sei lá, escrevi um negócio, rasgou o papel e aí eu... saio de mim: "Nunca mais venho nesse hospital, eu odeio isso aquil!" (todos sorriem muito, a participante gesticula, simulando desespero). Eu tenho essas flutuações emocionais. Ridículo! (Grupo 1).

A prevalência da síndrome de burnout entre profissionais da área da saúde é elevada, variando de $50 \%$ a $74 \%$. Entre os estudantes de Medicina, a prevalência fica em torno de $25 \%{ }^{16}$. Como a síndrome está intimamente relacionada a condições psicológicas, estresse exacerbado e insatisfação, não foi surpresa encontrar sintomas da síndrome entre os participantes desta pesquisa. Feijó et al. ${ }^{33}$ afirmam que o sentimento de frustração é comum entre os estudantes de Medicina, principalmente por causa da falta de apoio oferecido pelos professores e da sobrecarga de atividades acadêmicas, realidade presente no grupo estudado.

\begin{abstract}
A pessoa te cobra que você saiba fazer com excelência, e tem que ser no tempo dela, porque é assim que tem que ser feito, é assim que sempre foi feito. E é isso que eu acho: vai realmente esgotando porque você tem uma necessidade de uma outra pessoa que você tem que cumprir, sabe? A gente não consegue! Tem momentos que a gente realmente não consegue, assim... e esgota mesmo. Esgotamento é a palavra que consegue resumir o internato (Grupo 2).
\end{abstract}

Esse foi o único momento em que a palavra esgotamento foi utilizada para nomear o estágio e não a condição do sujeito.

A automedicação é apontada como uma das estratégias usadas pelos estudantes para que eles possam dar conta das demandas do curso e lidar com os sintomas do sofrimento. Eles se apropriam dos fatores que predispõem a automedicação, como falta de tempo para ir ao médico, confiança no conhecimento adquirido, contato com as medicações e com profissionais de saúde ${ }^{34}$. Outrossim, destacamos o efeito da internalização do papel de profissional: "A gente também se cobra a se curar sozinho, a ter esse poder que é colocado na gente. Se a gente tem que curar alguém, por que a gente não pode se curar?" (Grupo 1).

Apesar de todo esse processo ser vivenciado em grupo, o silenciamento sobre o cansaço e o sofrimento produz um pacto de superação, uma esperança de término que alivia, mesmo que temporariamente, as dores do presente.

O curso impõe coisas para você fazer que não tem como escolher fazer ou não, tem que fazer! $E$ isso é uma carga muito grande, tem hora que você não dá conta... quer dizer, tem uma hora que acaba e por isso você deu conta! E passa para o próximo... e você vai indo, entendeu? Porque todo mundo passou, todo mundo vence, e uma hora você vai conseguir... e você venceu... (Grupo 2).

\section{CONCLUSÃO}

\section{Trilhando respostas e tecendo esperanças}

"E aí a gente caiu aqui no sexto ano e não tem vida para colocar nesse tempo! E aí? O que eu vou fazer? O que eu vou fazer com isso? 'Eu acho que eu virei fazer um plantão no hospital' [risos]. Minha vida está toda em certificados" (Grupo 1).

Acreditamos que a maior contribuição desta pesquisa foi demonstrar como a distribuição do (não)tempo tornase um dispositivo de controle sobre os estudantes. Subtrair o tempo é retirar do sujeito a possibilidade de pensar e, consequentemente, a liberdade de escolher. Torna-se um processo sutil de desumanização.

Ao mesmo tempo que o sofrimento forja um sujeito forte, com competências para enfrentar a vida e a morte, a naturalização dessa dor produz um indivíduo que não se reconhece no outro, a quem não é permitido sofrer - uma distinção que não apenas diferencia, mas também desumaniza. Essa banalização do sofrimento, que funciona como uma defesa para suavizar a dura realidade na qual os estudantes vivem, acaba por gerar uma impossibilidade de cuidar (de si e do outro), pois nega as vulnerabilidades.

O processo de ensino-aprendizagem adotado no estágio supervisionado necessita ser reavaliado pelos envolvidos. Não é possível uma relação ensino-serviço na qual os lugares são confusos e parecem anular todo o investimento pedagógico que orienta o currículo nos outros ciclos da graduação. Para isso, o conhecimento sobre burnout, resposta emocional ao estresse crônico, parece ser peça-chave para rever questões institucionais que contribuam para a qualificação do ensino médico.

É preciso construir pontes para devolver aos estudantes no internato a condição de aprendiz e o direito a 
ter uma formação de fato, conforme preconizam as Diretrizes Curriculares Nacionais (DCN), para que, em novas pesquisas, frases como a do grupo 2 indicada a seguir não retornem mais ao final dos encontros:

\section{Mediadora: E a vida? Como é que fica?}

Grupo 2: Vida? Que vida?

\section{AGRADECIMENTO}

Agradecemos à Junia Roara o trabalho primoroso na condução dos grupos focais.

\section{CONTRIBUIÇÃO DAS AUTORAS}

$\mathrm{O}$ artigo foi concebido pelas três autoras. Flávia do Bonsucesso Teixeira e Suellen Magalhães Dias Oliveira foram responsáveis pela curadoria e análise dos dados e pela discussão dos resultados. Mariana Hasse participou da discussão dos resultados e da revisão final.

\section{CONFLITO DE INTERESSES}

As autoras declaram não haver conflito de interesses neste estudo.

\section{FINANCIAMENTO}

Declaramos que não houve financiamento para a realização desta pesquisa.

\section{REFERÊNCIAS}

1. Costa EFO, Santos SA, Santos ATRA, Melo EV, Andrade TM. Burnout syndrome and associated factors among medical students: a crosssectional study. Clinics. 2012;67(6):573-80.

2. Cândido J, Souza LR. Síndrome de burnout: as novas formas de trabalho que adoecem. Psicologia.pt. 2016 [acesso em 18 maio 2020]. Disponível em https://www.psicologia.pt/artigos/textos/A1054.pdf.

3. Maslach C, Jackson SE, Leiter MP. Maslach Burnout inventory. In: Zalaquett CP, Wood RJ, editors. Evaluating stress: a book of resources. 3rd ed. Palo Alto, CA: Consulting Psychologist's Press, 1996.

4. Vieira I. Conceito(s) de burnout: questões atuais da pesquisa e a contribuição da clínica. Rev Bras Saúde Ocup. 201035(122):269-76 [acesso em 18 maio 2020]. Disponível em: http://www.scielo.br/scielo. php?script=sci_arttext\&pid=S0303-76572010000200009\&lng=en .

5. Pêgo FPL, Pêgo DR. Síndrome de burnout. Rev Bras Med Trab. 2016;14(2):171-6.

6. Peckham C. Medscape Lifestyle Report 2017: Race and Ethnicity, Bias and Burnout. 2017 [acesso em 18 maio 2020]. Disponível em: https://www. medscape.com/features/slideshow/lifestyle/2017/overview\#page=2\&gt.

7. Davenport L. Taxa alarmante de burnout em estudantes de medicina. Medscape. 2018 [acesso em 18 maio 2020]. Disponível em: https:// portugues.medscape.com/verartigo/6502138\#vp_2.

8. Enns SC, Perotta B, Paro HB, Gannam S, Peleias M, Mayer FB, et al. Medical students' perception of their educational environment and quality of life: is there a positive association? Acad Med. 2016;91(3):409-17.

9. Santa ND, Cantilino A. Suicídio entre médicos e estudantes de medicina: revisão de literatura. Rev Bras Educ Med. 2016;40(4):772-80.

10. Conceição LS, Batista CB, Dâmaso JGB, Pereira BS, Carniele RC, Pereira GS. Saúde mental dos estudantes de medicina brasileiros: uma revisão sistemática da literatura. Avaliação: Revista da Avaliação da Educação
Superior (Campinas). 2019;24(3):785-802.

11. Marafanti I, D'elia G, Pinheiro MCP, Cordeiro Q, Alves TCTF. Influência de sintomas ansiosos no desempenho acadêmico de formandos de medicina. Arq Méd Hosp Fac Ciênc Med Santa Casa São Paulo. 2013;58:18-23.

12. Tempski P, Bellodi PL, Paro HB, Enns SC, Martins MA, Schraiber LB. What do medical students think about their quality of life? A qualitative study. BMC Med Educ. 2012;58(12):106-113.

13. Mota ID, Farias GO, Silva R, Folleet A. Síndrome de burnout em estudantes universitários: um olhar sobre as investigações. Motrivivência (Florianópolis). 2017;29(esp):243-56.

14. Dias EC. Condições de trabalho e saúde dos médicos: uma questão negligenciada e um desafio para a Associação Nacional de Medicina do Trabalho. Rev Bras Med Trab. 2015;13(2):60-8.

15. Freitas WRS, Jabbour CJC. Utilizando estudo de caso(s) como estratégia de pesquisa qualitativa: boas práticas e sugestões. Estudo \& Debate. 2011;18(2):7-22.

16. Taliberti BB. Escola de Medicina e Cirurgia de Uberlândia: registros históricos. Araguari: Minas; 2017. 432 p.

17. Backes DS, Colomé JS, Erdmann RH, Lunardi VL. Grupo focal como técnica de coleta e análise de dados em pesquisas qualitativas. Mundo Saude. 2011;35(4):438-42.

18. Bardin L. Análise de conteúdo. Lisboa: Edições 70; 1977.

19. Gonçalves CIRVB. Síndrome de burnout em estudantes de Medicina [dissertação]. Porto: Universidade do Porto; 2016.

20. Universidade Federal de Uberlândia. Aprova as Normas Gerais de Estágio de Graduação da Universidade Federal de Uberlândia, e dá outras providências. Resolução n 24, de 25 de outubro de 2012.

21. Universidade Federal de Uberlândia. Normas do Estágio Curricular Obrigatório em Medicina: Internato. Uberlândia: UFU; 2014.

22. Universidade Federal de Uberlândia. Projeto Pedagógico do Curso de Medicina. Uberlândia: UFU; 2012 [acesso em 17 jun 2020]. Disponível em: http://www.famed.ufu.br/system/files/conteudo/pp2012_22-08-2013.pdf.

23. Prado MSFM, Norte NM, Carvalho IGM, Souza IF, Almeida RJ. Avaliação da síndrome de burnout entre estudantes do último ano de um curso de medicina do Brasil. Arq Ciênc Saúde. 2019; 26(1):41-6.

24. Autonomo FROM, Hortale VA, Santos GB, Botti SHO. A preceptoria na formação médica e multiprofissional com ênfase na atenção primária análise das publicações brasileiras. Rev Bras Educ Med. 2015;39(2):316-27. doi: 10.1590/1981-52712015v39n2e02602014.

25. Câmara Temática do Médico Jovem. Assédio moral. São Paulo: Cremesp; 2019

26. Fernandes L, Basilio N, Figueira S, Nunes JM. Saúde mental em medicina geral familiar - obstáculos e expectativas percecionados pelos médicos de família. Ciênc. Saúde Colet. 2017; 22(3): 797-805.

27. Gracino ME, Zitta ALL, Mangili OC, Massuda EM. A saúde física e mental do profissional médico: uma revisão sistemática. Saúde Debate. 2016;40(110):244-63.

28. Vieira EM, Hasse M. Percepções dos profissionais de uma rede intersetorial sobre o atendimento a mulheres em situação de violência. Interface (Botucatu). 2017;21(60):52-62.

29. Sá MC, Azevedo CS. Subjetividade e gestão: explorando as articulações psicossociais no trabalho gerencial e no trabalho em saúde. In: Azevedo $C S$, Sá MC, orgnizadoras. Subjetividade, gestão e cuidado em saúde: abordagens da psicossociologia. Rio de Janeiro: Fiocruz; 2013. p. 33-51.

30. Santa ND, Cantilino A. Suicídio entre médicos e estudantes de Medicina: revisão de literatura. Rev Bras Educ Med. 2016;40(4):772-80.

31. Hasse M, Oliveira BC, Souza CG, Pereira DBS, Barros MCV, Hattori WT. Assédio na formação médica e o trabalho de(o)cente. Anais do $2^{\circ}$ Seminário Nacional sobre Saúde e Trabalho; 2017, Manaus, Universidade Federal do Amazonas, 1(1):26-27.

32. Barreto MAM, Reis CN, Miranda IB, Jardim LCR, Teixeira MP. Ser médico: o imaginário coletivo de estudantes de medicina acerca da profissão de médico. Cadernos Unifoa. 2009;4(11):73-6. 
33. Feijó DH, Mainardi CR, Valente AL, Yamaki VN, Teixeira RKC, Silva JAC. Dilemas e frustrações do estudante de medicina: estudo transversal. Para Res Med J. 2018;1 (2):1-6.
34. Silva R, Oliveira T, Casimiro T, Vieira K, Tardivo M, Faria Junior $M$, et al. Automedicação em acadêmicos do curso de medicina. Medicina (Ribeirao Preto, Online). 2012;45(1):5-11 [acesso em 17 jun 2020]. Disponível em: http://www.revistas.usp.br/rmrp/article/view/47477. 